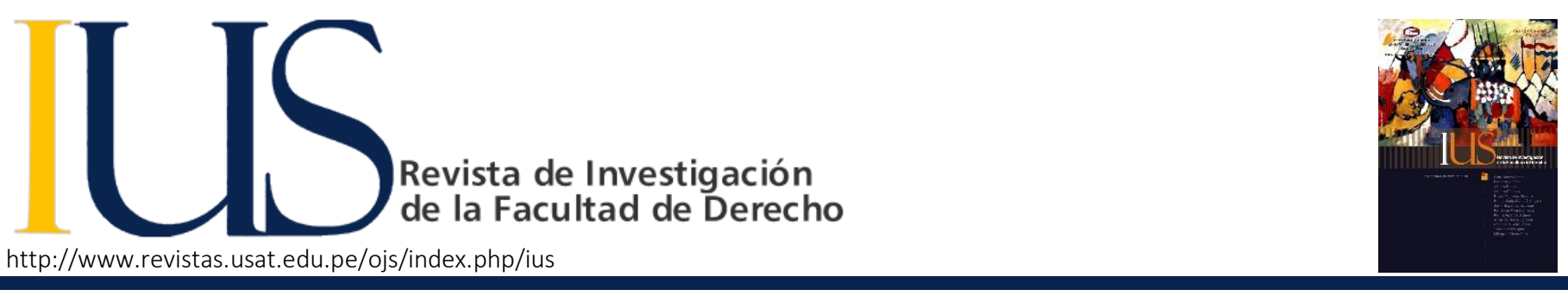

\title{
Breves consideraciones acerca del Precedente Administrativo
}

\author{
Tomás Hutchinson ${ }^{1}$, Alberto Biglieri²
}

\begin{tabular}{ll}
\hline INFORMACIÓN DEL ARTÍCULO & RESUMEN \\
\hline Historia del artículo: & Los autores realizan un breve análisis de la naturaleza y características del "precedente \\
Recibido el 10 de mayo de 2012 & administrativo" como instituto propio de la disciplina del Derecho Administrativo así \\
Aceptado el 15 de junio de 2012 & como la importancia de sus efectos y su tratamiento en el ordenamiento jurídico \\
& argentino, haciendo una breve comparación con las legislaciones española y peruana. \\
\hline Palabras claves: & lgualmente establecen las diferencias entre este instituto y figuras jurídicas como la \\
Precedente administrativo & costumbre, la jurisprudencia, el precedente vinculante, las prácticas administrativas y \\
Costumbre & los actos propios de la administración. Finalmente señalan que este concepto refuerza \\
Jurisprudencia administrativa & la justicia y la seguridad jurídica en los pronunciamientos motivados que debe emitir la \\
Principio de juridicidad & Administración Pública. \\
Precedente vinculante & Prácticas administrativas
\end{tabular}

\section{Introducción}

La historia de la humanidad está preñada de precedentes. Más aún, en las cuestiones sociales, políticas, jurídicas y económicas, la interrupción del devenir cotidiano de los hechos o acontecimientos es la que necesita una argumentación o explicación especial.

La cotidianidad, lo previsto y lo previsible se encadenan en las conductas sociales $y$, por ello, se imponen como límites usuales de las acciones del hombre en su comunidad. El derecho privado se aferra a la justicia que implica la repetición de los propios actos de cada individuo, en el marco de las expectativas que acunan los terceros ante las conductas conocidas del actor principal del hecho o acto, dejando a salvo que las razones debidamente justificadas para el cambio, se presentan como el ámbito de resguardo de la libertad y del libre albedrío de optar ante todas las posibilidades no prohibidas por las leyes. En este caso, se adivina la dificultad de recepción en el derecho administrativo de este principio general del derecho privado, característico de la capacidad de las personas, y en abierta tensión con el principio de competencia, natural de nuestra especialidad.
Este fenómeno, anclado en la utilización que hacemos de los antecedentes en el derecho, está caracterizado especialmente en la filosofía y la lógica. En estas ciencias, el precedente constituye uno de los elementos centrales de sus herramientas: los silogismos. Allí, de términos precedentes verdaderos se arribará a consecuentes correctos. También aparece, ante la simple pronunciación del término, una noción de orden cronológico en nuestra aproximación al conocimiento, que se impone antes que la razón o la lógica del orden de los términos.

Así: " la precedencia racional, aplicada al ritmo del tiempo, es la base de la previsión, verdadero distintivo del hombre, pues como dice Schopenhauer, el animal vive solo en el presente. Efecto de tal precedencia racional es la presciencia, que, aun dentro de sus límites, puede adquirir el intelecto humano presciencia que se aplica a todas las esferas de la vida, señaladamente a la moral"13.

$Y$, ¿qué es esto de la presciencia?: Según la Real Academia es el "Conocimiento de las cosas futuras". En esto plantamos nuestra posición inicial: el derecho administrativo necesita, cada vez con más urgencia, dotar de institutos al derecho

\footnotetext{
${ }^{1}$ Profesor Titular Emérito de la Universidad de Buenos Aires. Profesor Titular Ordinario de Derecho Administrativo II de la UNLP. Profesor Titular Ordinario de Derecho Administrativo de la UNMDP. Presidente del Tribunal de Disciplina del Colegio Público de Abogados de la Capital Federal.Ex Juez del Superior Tribunal de Justicia de la Provincia d Tierra del Fuego. Ex Juez de la Camara Federal en los Contencioso Administrativo de la Capital Federal. Argentina.

2 Profesor Titular Ordinario de Derecho Administrativo de la UNLZ. Profesor Adjunto Regular de Derecho de la Integración de la Universidad de Buenos Aires. Profesor Titular de Derecho Municipal de la UNLZ. Subdirector del Instituto de Derecho Administrativo del Colegio Público de Abogados de la Capital Federal. Director de la Caja de Previsión Social para abogados de la Provincia de Buenos Aires. Argentina.

${ }^{3}$ Diccionario Enciclopédico Hispano - americano de Literatura, Ciencias y Artes. Montaner y Simon Editores. Barcelona. España. 1895. T* XVI. P. 213
} 
público que garanticen la confianza, las expectativas legítimas y la buena fe en las relaciones en las que el Estado es parte, aún con el esfuerzo que proponemos al no contar con norma positiva que entronice al precedente administrativo como efecto de esas bondades que, al fin y al cabo, se han transformado en patrimonio de los principios generales de todo el derecho.

Por cierto, la Real Academia aporta simpleza a la utilización o reconocimiento de la naturaleza de las palabras que nos permiten comunicarnos y presentar nuestros postulados, el abogar necesita indispensablemente de estas herramientas y en muchas ocasiones se robustecen dentro de la jerga o vocabulario abogadil.

Debemos aclarar que no abordaremos el complejo y extenso instituto del precedente judicial y su efecto normativo en el primero de ellos, y sí nos remitiremos a muchas experiencias y referencias al segundo. Trabajaremos sobre este ítem dada la importancia trascendental del derecho público histórico español ${ }^{4}$, en especial para nosotros y para la Latinoamérica de habla hispana, que más allá del modelo constitucional implantado luego de las independencias, fue la receptora de una administración pública funcionando con sistemas y reglas que aún subsisten y siguen generando precedentes ${ }^{5}$.

Por otra parte, adelantamos, que la referencia y análisis realizado sobre la más actual doctrina española, no implica aconsejar su seguimiento, pues esa escuela está enancada en ampliar los límites del principio de legalidad atribuyendo más margen de discrecionalidad a gobiernos estatales ${ }^{6}$ ante los órganos u organismos comunitarios.

La historia común latinoamericana, no necesariamente ha tenido consecuencias comunes en los procesos constitucionales del independentismo de los territorios virreinales. En el viejo continente, la amplitud del neoconstitucionalismo español al combinarse con la fenomenal delegación de potestades públicas en el marco de la integración europea las autoridades supranacionales, genera una reconstrucción permanente del esquema y las opciones en la toma de decisiones en el poder que son inadmisibles en estos lares, con estas administraciones públicas y nuestra cultura política actual. Otro ejemplo de desarrollo disímil, adentro del subcontinente y mucho más importante para el tema a desarrollar por la atribución positiva de fuerza al instituto del precedente administrativo, es el caso de las legislaciones peruana y colombiana ${ }^{7}$ en la que las normas positivas infunden a aquél la fuerza de las

${ }^{4}$ BIGLIERI, ALBERTO, Estudios de Derecho Municipal, Ediciones Jurídicas. Buenos Aires 2010, p. 26.

${ }^{5}$ En España, el Fuero Juzgo del siglo XIII - y sus precedentes - se continuaron utilizando hasta el Siglo XIX, y aún hoy se memora y se cita en decisiones en Aragón, Navarra y en el País Vasco.

${ }^{6}$ Remitimos a los textos de RAMÓN PARADA VÁZQUEZ, SILVIA DIEZ SASTRE, FRANCISCO VELASCO CABALLERO, y de DIEZ PICASO.

7 En Perú: "Ley 27445 del Procedimiento administrativo general. En Colombia: "Ley 1437 de 2011 Diario Oficial No. 47.956 de 18 de enero de 2011.

8 Parece que el término "precedente" tuvo su origen en el lenguaje parlamentario, aunque hoy es explícitamente usado en el Derecho Administrativo.

${ }^{9}$ Así ha dicho que "El precedente administrativo es aquella actuación pasada que, de algún modo, tiene aptitud para condicionar las actuaciones características de la jurisprudencia judicial obligatoria (efectos que en nuestro país tienen escasa aparición legislativa, como por ejemplo la atribuida a los fallos plenarios en las Cámaras Federales de Apelación del fuero penal).

\section{EL PRECEDENTE ADMINISTRATIVO}

\subsection{Noción}

Del latín praecedents,-tis, participio activo de praecedere, significa, primeramente, algo que es anterior o primero en orden (en tiempo). En la terminología jurídica el uso de tal vocablo se encuentra íntimamente relacionado con su significado en el lenguaje ordinario. Precedente es sinónimo de antecedente; se refiere a una ocurrencia anterior de un hecho similar, y designa un hecho o circunstancia relacionado, de alguna manera relevante con un hecho anterior con el que se compara $)^{8}$. En un sentido más limitado, precedente señala una instancia o acción que constituye parte de una práctica ya iniciada, o bien, modelo o patrón de una práctica subsecuente.

Se puede trazar un concepto del precedente administrativo, acudiendo a sus caracteres, que permiten diferenciarlo de las distintas fuentes del derecho administrativo, con las que se le suele confundir. Es, sin duda, y por lo general, una fuente escrita, que se contrapone a la costumbre y a la praxis administrativa, ambas no escritas y que, a semejanza de éstas, se construye a través del procedimiento inductivo, es decir, que de una serie de casos concretos (para el caso bastan sólo dos) se induce la norma o regla general de la igualdad, a diferencia de la ley, que fija las normas generales, más tarde detalladas y aplicadas a los supuestos particulares. La formación, por lo tanto, del precedente se produce mediante una operación de abstracción del principio general a través de casos particulares y determinados.

La Procuración del Tesoro de la Nación, faro de las opiniones jurídicas de la estructura administrativa del estado federal, hace un aporte al abordaje lingüístico del tema, y por ello es conveniente citar algunos ejemplos de la utilización de la noción precedente administrativo que utiliza el órgano rector de la abogacía estatal federal argentina ${ }^{9}$.

Nos referiremos a los actos administrativos, en tanto que declaraciones con efectos jurídicos directos e individuales cuya aparición en el mundo jurídico implica un valor deseable $y$, por lo tanto, sanamente repetible para el accionar administrativo. La doctrina, sigue la noción que acuñó DIEZ-

presentes de la Administración, exigiéndoles un contenido similar para casos similares" (PTN, Dictámenes 236:091. http://www.ptn.gov.ar/Dictamenes/s236-091.htm), señalando, además que: "Nadie tiene en principio un derecho adquirido al mantenimiento de leyes ni de criterios jurisprudenciales, por lo que tampoco resulta razonable invocar su existencia frente a un cambio de criterio de precedentes administrativos, en especial cuando las circunstancias exigen la evaluación de cada caso en concreto (PTN, Dictámenes 236:091. http://www.ptn.gov.ar/Dictamenes/s236-091.htm ). Añadió que: "Los precedentes administrativos carecen de efec- to vinculante en tanto no existe norma legal que constriña a la Administración a dictar sus decisiones de acuerdo a lo obrado en casos anteriores; en efecto, no obligan a la Administración a conformar su voluntad de idéntica manera cuando existan razones fundadas para expedirse en un sentido diferente (PTN, Dictámenes 236:091. http://www.ptn.gov.ar/Dictamenes/s236-091.htm). 
PICASO ${ }^{10}$ según la cual: "El precedente administrativo es aquella actuación pasada de la Administración que, de algún modo, condiciona sus actuaciones presentes exigiéndoles un contenido similar para casos similares".

\subsection{El precedente administrativo: su diferencia con el judicial}

Interesa aclarar la terminología a efectos de optimizar el análisis que se hará en estas páginas: el precedente administrativo existe en el marco del procedimiento administrativo, a diferencia del llamado precedente judicial administrativo, cuya dimensión existencial es el ámbito tribunalicio. El primero se conforma a partir de una decisión final de un órgano competente cuya importancia económica, jurídica, social o política - alienta e invita a repetirla en casos similares. El precedente judicial controla y revisa la validez de la decisión, emergiendo con todos los efectos inherentes al fallo y las propias características de la función judicial (cosa juzgada, irreversibilidad, estabilidad, etc.). Por último, será necesario compararlos con otras figuras de utilización corriente en la disciplina: la costumbre, la jurisprudencia administrativa, la motivación y el respecto del principio de que no cabe ir contra los propios actos de la administración, pues en general, la doctrina nacional tradicional ha incluido alguna mención al precedente administrativo en los desarrollos de estos institutos y figuras recién señaladas, y se registran pocos trabajos que aborden el tema directamente ${ }^{11}$.

\subsection{Diferencias con la costumbre y la jurisprudencia administrativa}

La tradición o la costumbre - por su denominación como fuente del derecho ${ }^{12}$-constituye una norma no escrita, fácilmente reclamable entre los particulares. Pero para el caso que nos ocupa, y a partir del indiscutido reconocimiento del principio de juridicidad - omnicomprensivo de la vigencia

${ }^{10}$ DIEZ PICASO PONCE DE LEÓN, LUIS MARÍA, La doctrina del precedente administrativo www.cepc.es/rap/ publicaciones/revistas/1/1982098 007.pdf. p. 7.

${ }^{11}$ Entre ellos, IVANEGA, MIRIAM MABEL, Los precedentes administrativos en el derecho argentino, en Fuentes del derecho administrativo (IX Foro Iberoamericano de Derecho Administrativo, 2010, Mendoza, Argentina), ed. Régimen de Administración Pública, Buenos Aires, 2010, p. 67/80, CAPUTI, M. CLAUDIA, La coherencia del comportamiento administrativo, Revista de Derecho Administrativo, vol. 16, no 50, Buenos Aires, 2004, p. 879. COMADIRA, GUILLERMO, Los precedentes administrativos, en VV. AA., Cuestiones de Acto Administrativo, Reglamento y otras fuentes del Derecho Administrativo, Jornadas organizadas por la Facultad de Derecho de la Universidad Austral, Buenos Aires, Ediciones RAP, 2009, p. 321 y MONTARON ESTRADA, GLORIA, La práctica administrativa como fuente del Derecho Administrativo, La Ley, 5-VI-2009, p.1.

12 GORDILLO, AGUSTÍN, Tratado de Derecho Administrativo, ed. Fundación Derecho Administrativo, Buenos Aires, 2009, T 1, p. VII 72. Delimita claramente la diferencia entre la costumbre, lisa y llanamente admitida como fuen- te, de la jurisprudencia que recepta alguna costumbre.

${ }^{13}$ GORDILLO, A., Tratado, cit., T. 1, p. VII 73, agrega la expansión del principio de legalidad en alguna materia del derecho privado -comercial- , como para marcas y patentes.

${ }^{14}$ Vinculante, en tanto que nos referimos al seguimiento "intelectual" que debe el órgano asesor desconcentrado o descentralizado de la Administración Federal al dictamen emanado de la PTN sobre similar objeto, situación y relación. Al referirnos a la incidencia del dictamen en el marco de las obligaciones emergentes de todas las normas validas, y obviamente inclusivo del principio de juridicidad -, se necesita una norma previa determinante del derecho administrativo en cuestión, - más laxo, pero análogo al penal y al tributario ${ }^{13}$-, que requieren imprescindiblemente la norma como único vehículo de validez.

En esta disciplina, la costumbre opera como fuente indirecta para la Administración y solo puede ser argumentada directamente por el ciudadano para oponerse a los excesos reglamentarios incumplidos por el Estado. Nos estamos refiriendo aquí, al grado de incidencia que trasunta la costumbre sobre la actividad normativa del Estado.

Es menester aclarar que muy cercano a estas ideas aparece otro instituto típico del derecho administrativo que queremos desechar rápidamente para no confundirlo con el precedente administrativo que nos ocupa: la jurisprudencia administrativa y el seguimiento obligatorio que produce sobre los simples actos de la administración con efecto vinculante ${ }^{14}$ en el seno de la jerarquía intelectual de la abogacía estatal. En oportunidad de sistematizar el estudio de los efectos de la jurisprudencia en el derecho administrativo ${ }^{15}$, nos inclinamos por dividir la usual clasificación de esta fuente en dos grandes grupos seleccionados por la naturaleza jurídica del órgano emisor. Llamamos jurisprudencia judicial administrativa a aquella emisión de decisiones de los órganos judiciales sobre objetos y relaciones abordadas desde el derecho público, y jurisprudencia administrativa a las opiniones emitidas por los órganos de la abogacía estatal (v. gr. Procuración del Tesoro de la Nación) cuyo seguimiento es obligatorio para los órganos asesores de la administración pública que integran. Ese seguimiento obligatorio, vinculante, proporciona un valor agregado a ese tipo de opiniones. Sostenemos que no debe confundirse estas instituciones con la jurisprudencia judicial y toda su carga expuesta en la fuerza de las sentencias y fallos ${ }^{16}$. Por otra parte, ese efecto vinculante lo es, solo, para

del artículo 7 de la LNPA, hemos dicho:" Ia LNPA, pensada para la gigantesca estructura del poder federal, establece indefectiblemente la necesidad de la opinión jurídica previa sobre el caso, y a la vez induce a que esta guarde armonía de criterios con los utilizados por las demás dependencias del PEN. Que la opinión provenga de los servicios permanentes implica conocimientos técnicos, estabilidad, independencia del poder político y homogeneidad de criterios con los sustentados por la Procuración del Tesoro de la Nación. Y que sea un elemento esencial del AA dependerá de que en el tema a tratar se puedan afectar derechos subjetivos e intereses legítimos", en BIGLIERI, ALBERTO, Manual de Derecho Administrativo, La Ley, Buenos Aires, 2011, p. 207.

15 BIGLIERI, A., Poder de policía y Fomento en HUTCHINSON, TOMÁS (DIRECTOR) Tratado doctrinario y jurispru- dencial de Derecho Administrativo, Volumen III, T. 1, p. 26

${ }^{16}$ Hemos sostenido, a la hora de ordenar el análisis de las fuentes del derecho administrativo en HUTCHINSON. T. (DIR) Tratado, cit., Volumen III, $\mathrm{T}^{\circ}$ I, p. 26, que: "la gran recepción de fuentes que realiza el Derecho Administrativo, se traduce a la vez en una enorme producción jurisprudencial de distintos órganos judiciales del Estado Nacional, Provincial, de la Ciudad Autónoma. Es que la interpretación de la activa vida normativa del derecho público importa la aplicación de normas formales y sustantivas en cada una de nuestras organizaciones públicas estatales y privadas con atribuciones administrativas para la satisfacción de las finalidades públicas. Aún más, nuestra especialidad incorpora la noción de Jurisprudencia administrativa, para calificar la emisión de opiniones y decisiones de órganos administrativos (no judiciales) de los distintos niveles 
la "jerarquía técnica" que impone la legislación a los órganos asesores con competencia científica o especializada, que insertos en cualquier estructura de la Administración centralizada, desconcentrada o descentralizada - deben igualmente respeto y seguimiento a ese saber emanado de los dictámenes de la Procuración del Tesoro, independientemente del otro respeto jerárquico usual, que corresponde prestar al órgano activo jerárquicamente superior con competencia decisoria .

En relación a la diferencia que el instituto que analizamos y las prácticas administrativas ${ }^{17}$ ostentan ante la costumbre en un ámbito de derecho público positivo, PARADA VÁZQUEZ ${ }^{18}$ se explaya: "En todo caso, las prácticas y los precedentes se distinguen de la costumbre en que: a) se trata de reglas deducidas del comportamiento de la Administración sin intervención de los administrados, cuya conducta es aquí irrelevante; b) la práctica o el precedente no tienen por qué estar avalados como la costumbre por un cierto grado de reiteración o antigüedad, bastando, como se dijo, un solo comportamiento en el caso del precedente.

Estas notas diferenciales son las que justifican las dudas sobre la asimilación de las prácticas y precedentes con la costumbre, problema nada baladí, por cuanto las prácticas y precedentes tienen una importancia real en la vida administrativa y al precedente se le reconoce un cierto grado de obligatoriedad en el art. 54.1.c) de la Ley de Régimen Jurídico de las Administraciones Públicas y del Procedimiento Administrativo Común, al obligar a la Administración a motivar aquellas resoluciones "que se separen del criterio seguido en actuaciones precedentes".

\subsection{Precedente y motivación}

No aparece demasiado atractivo el conocimiento o utilización y cita de precedentes administrativos en actos cuya emisión se encuentre fuertemente apegada al reglamento. El mayor ámbito de discrecionalidad aparece como un territorio fértil para citar y recordar precedentes administrativos especialmente utilizados como figuras argumentativas de la motivación administrativa. Los actos administrativos corrientes, estereotipados, en los que el reglamento y la previsión ordenan ágilmente la voluntad de la administración, no se esfuerzan en la justificación que se plasma en el elemento motivación.

Destacamos que "la motivación del acto administrativo tiene por objeto exteriorizar el iter sicológico que ha inducido al titular del órgano a dictar el acto de tal forma que haga

de la estructura estatal - Nacional, Provincial, de la Ciudad Autónoma y de la Municipalidad de Buenos Aires - cuya labor es una fuente importantísima de nuestra disciplina y la trataremos en este espacio. Consideramos trascendente esta reseña, pues como lo enseñara Revidatti y lo plasmara en la Ley de Procedimientos Administrativos de Corrientes, esta inmensa masa crítica de producción jurídica, es el núcleo básico de las experiencias de mejor calidad y referencia para la búsqueda de soluciones analógicas en el Derecho Público. Para agilizar la tarea, las búsquedas y las lecturas, este análisis jurisprudencial se dividirá en tres ramas principales: Jurisprudencia Judicial, Jurisprudencia Administrativa y Jurisprudencia arbitral".

17 Sobre las que volveremos en el punto 6.

18 ARADA VÁZQUEZ, RAMÓN, Derecho Administrativo, Marcial Pons, Madrid, 2010, t. I, p. 83 posible conocer los momentos fundamentales del razonamiento" 19 y calificamos la exigencia como que "es indispensable para poder apreciar si se ha satisfecho la finalidad prevista en la norma que otorga facultades al órgano para emitir el acto" ${ }^{20}$. En esa línea - más rígida y basada en la manda de la Ley española de Procedimientos, LRJPAC, art. 54.1.c - SILVIA DIEZ SASTRE señala que "es común que los particulares ante un acto negativo o desfavorable, por ejemplo, la denegación de una licencia, acudan a los tribunales alegando la existencia de un cambio de criterio injustificado por parte de la Administración" ${ }^{21}$, que obviamente afecta el principio de igualdad.

Por el contrario la amplitud de los márgenes de la discrecionalidad lleva a recurrir, en muchas ocasiones a la hora de sostener y fundar una resolución, a comparaciones valorativas sobre decisiones administrativas anteriores de resultado positivo, que permiten "motivar" la conclusión del caso en desenlaces similares acaecidos anteriormente.

De alguna forma, el seguimiento del precedente - a diferencia de la jurisprudencia administrativa que tratamos más arriba que no es ni puede ser vinculante, se haya fuertemente impulsado desde los principios generales del derecho y de expresas garantías constitucionales como el principio de igualdad y la interdicción de arbitrariedad, tema desarrollado en profundidad, últimamente, por CASSAGNE ${ }^{22}$.

\subsection{El precedente es vinculante, ma non troppo}

Es difícil, al menos con nuestra práctica, escindir la relación cronológica existente entre el dictamen obligatorio y el vinculante ${ }^{23}$ y por lo tanto lograr borrar la analogía que se produce al echar mano del precedente administrativo. Si bien la inserción de éste en el nudo argumental de la motivación de los actos administrativos no es una obligación, su anotación generará una fuerza importante en el resultado final, a la que VELASCO CABALLERO llama "criterios moderados de vinculación".

Esto es indispensable. Aunque cueste muchos años inculcar la cultura de la ética, la transparencia y la honestidad en la función pública, se debe mantener la independencia y libertad de criterio del órgano activo, - por ejemplo en los casos de aptitud ambiental o fomento - para que el precedente administrativo no se transforme en un cepo o boomerang que al fortalecer el primer resolutorio de un caso concreto desapodere a la Administración de la amplitud que la norma le había conferido. Hay, pues, que analizarlo como una herramienta de control del principio de igualdad y no

${ }^{19}$ HUTCHINSON, TOMÁS, Régimen de procedimientos administrativos, 9 a ed., Astrea, Buenos Aires, 2010, p.90

${ }^{20}$ HUTCHINSON, TOMÁS, Régimen, cit., p. 90.

${ }^{21}$ DIEZ SASTRE, SILVIA, El precedente administrativo, Marcial Pons. Madrid. 2008. P.21.

${ }^{22}$ CASSAGNE, JUAN CARLOS, El principio de legalidad y el control judicial de la discrecionalidad administrativa Marcial Pons, Buenos Aires 2010, pp 35 y ss.

${ }^{23}$ A pesar de la escasa presencia de ese efecto en nuestro sistema, como ocurre en los dictámenes de pre adjudicación de ofertas o en las juntas médicas provisionales. 
como un cercenamiento de las potestades conferidas por el legislador a la Administración.

$\mathrm{Si}$ de igualdad estamos hablando, el instituto que comentamos se ha impuesto fuertemente en las prácticas del derecho previsional. En esta especialidad, la innumerable cantidad de casos similares, pero individuales y personalísimos a la vez, generan la "fama" de algunos decisorios, que, por primeros en el tiempo, concienzudamente razonados y claramente motivados, inducen a resoluciones similares en los casos posteriores. Así, el cambio de las condiciones de los años exigibles para la jubilación de abogados a raíz de la modificación de la ley 6716 de la Provincia de Buenos Aires y la creación de la Cuota Anual Obligatoria (CAO), generó el "precedente Mendive", replicado a la fecha en todos los expedientes de jubilación o pensión que siguieron a aquella expresión de la voluntad administrativa del organismo previsional ${ }^{24}$.

En esos casos de amplitud de opciones, puede servir también como un disparador de actos administrativos plurales o colectivos consecuentes a alguna decisión inicial que sirva de estándar o forma, como en el caso de las medidas erarias de impulsos ${ }^{25}$ o fomento económico, sin que implique en el objeto esa autolimitación que señalamos en el párrafo anterior; o vaya a desembocar en un reglamento. En este último supuesto, la "inspiración" de ese acto no constituiría un PA, sino un antecedente de derecho - y de hecho si el objeto lo contempla y se realiza - de los que las normas de procedimiento administrativo identifican como "causa".

\subsection{Precedente, práctica administrativa y propios actos de la Administración}

Si es un esfuerzo incorporar la idea de la fuerza con la que vive en el derecho local el precedente administrativo, puede aparecer más simple otra noción que se revela muy emparentada a aquellos: las prácticas administrativas. Éstas indican, además de la solución individual anterior de un caso similar, su repetición a lo largo del tiempo.

En este sentido, en la obra referida de PARADA VÁZQUEZ ${ }^{26}$, se señala una clara diferencia entre la noción de precedente administrativo y la de prácticas administrativas. Para el citado tratadista, esta última "supone una reiteración en la aplicación de un determinado criterio en casos anteriores", distinguiéndolo de aquél que puede haber aparecido una sola vez, en un caso análogo al que estamos estudiando.

En nuestro medio, y en esta especialidad, recurrimos innumerables veces a invocar las prácticas administrativas repetidas en el tiempo como actos propios o propios actos de

\footnotetext{
${ }^{24}$ Que obtuvo finalmente decisión judicial favorable, a pesar de la aplicación que ya hacía la Caja de Previsión.

${ }^{25}$ BIGLIERI, A., Poder de policía y Fomento en HUTCHINSON, T., Tratado, cit., Vol. 3, $T^{\circ}$ I, p. 479. "Como vemos, la utilización correcta del idioma y sus fuentes históricas nos deparan una enorme cantidad de sorpresas. Muchas expresiones se ven en la actualidad, pretendiendo aplicar la igualdad de trato entre el fisco y los particulares, sobre la base de las referencias anteriormente transcriptas. Aún en el rechazo de los excesos de los organismos recaudadores y sus intentos jurisdiccionales, felizmente limitados en fallos ejemplares como el reciente pronunciamiento de la Corte Suprema de Justicia en el caso INTERCORP, no nos adherimos a admitir la igualdad histórica entre las nociones de fisco y erario, y por ende a que los
}

la Administración, en orden a generar un elemento coadyuvante y de colaboración para la consolidación de la seguridad jurídica ${ }^{27}$. En el dictamen de la Procuración del Tesoro de la Nación que citamos anteriormente ${ }^{28}$, se ha dicho que: "Para que la teoría de los actos propios pueda ser invocada contra la Administración Pública deben encontrarse reunidos ciertos requisitos, entre los que se cuenta la necesidad de que el acto precedente haya sido regularmente emanado del órgano competente", poniendo de manifiesto la obvia - pero indispensable - necesidad de la regularidad del acto inicial.

\subsection{Efectos del precedente administrativo}

Si bien, ya hemos acompañado la opinión de la Procuración en referencia a que: "Los precedentes administrativos carecen de efecto vinculante en tanto no existe norma legal que constriña a la Administración a dictar sus decisiones de acuerdo a lo obrado en casos anteriores; en efecto, no obligan a la Administración a conformar su voluntad de idéntica manera cuando existan razones fundadas para expedirse en un sentido diferente". Consideramos necesario ampliar o desarrollar esta idea, que obviamente debe imperar dentro de la estructura pública, como un ejercicio intelectual de argumentación jurídica.

Al varias veces repetido principio de igualdad, en tanto que finalidad y efecto deseado de mantenimiento de un criterio similar para casos similares, debemos agregar que la repetición pacifica de precedentes en actos administrativos actuales similares aportan, a nuestro entender: a) justicia: resultado directo de tratar con uniformidad los casos cuyos antecedentes de hecho y de derechos similares, impulsen resoluciones similares; b) seguridad jurídica: La previsibilidad del accionar de la Administración es un reclamo ciudadano y un derecho claramente exigible a las autoridades. Los tiempos de la globalización, le agregan el valor de considerar a la seguridad jurídica una atracción especial para las inversiones internacionales. c) eficiencia y economía procedimental: la predecibilidad aporta presciencia y de ellas surge una suerte de "de presión de los reclamos" o una corriente de "reclamos posibles" a las que se suman rápidamente los interesados. El reclamo justo y el silencio de la pretensión excesiva, ahorran importantísimos volúmenes de fondos públicos. Ambos se morigeran ante el conocimiento cabal, continuo y respetuoso de la juridicidad y, ni los particulares ni la Administración necesitan llegar a incoar o responder respectivamente, recursos inútiles de difícil cuando no imposible- dilucidación judicial. d) la no

principios aplicables en el pasado a uno de esos institutos, se extienda al otro por la sola deformación idiomática de una sinonimia legislativa inconsistente con la fuente de la que abrevaban esos institutos diversos. ${ }^{26}$ PARADA VÁZQUEZ, R., Derecho, cit., p. 83.

${ }^{27}$ Es esta - la simple impulsión y la colaboración - la punta de la tensión que se ha analizado contra la positivización del instituto del precedente administrativo en el Derecho Público colombiano. Ver en SANTOFIMIO GAMBOA, JAIME ORLANDO: La fuerza de los precedentes administrativos en el sistema jurídico del derecho positivo colombiano, Universidad del Externado. Bogotá. Colombia. 2010.

${ }^{28}$ Ver nota 7. 
arbitrariedad: Como lo exige la Corte Interamericana, es exigible el límite que construye el principio de igualdad ante una decisión tomada en el ámbito de la discrecionalidad legítima, que aún permisivo de la opción administrativa, no encubre por ello el desvío de poder para beneficiar a algún particular en desmedro de una situación similar de otro interesado.

\section{DERECHO COMPARADO}

Como lo señalamos en la introducción, el constitucionalismo español y su legislación han incorporado en el bloque de juridicidad al precedente administrativo - como no podía ser de otra manera - en la normativa positiva del derecho administrativo español. Esta legitimidad ahorra los desarrollos doctrinales y los esfuerzos intelectuales que sobrellevamos quienes intentamos exigir o convencer a la Administración sobre las bondades de sostener sus criterios o motivar y explicar ampliamente el apartamiento de ellos, en un sistema como el argentino, que como ya hemos visto -y leído en la opinión de la Procuración del Tesoro de la Nación, no contiene normas positivas de valorización del precedente administrativo.

En Perú, la legislación también aporta la fuerza y claridad necesaria para regular la actividad administrativa con la incorporación expresa del instituto en estudio ${ }^{29}$. Por su parte, en Colombia, una redacción más compleja, atada a su estructura jurisdiccional de control administrativo - más del estilo francés -, también consagra al precedente en la norma positiva ${ }^{30}$.

\section{Conclusiones}

Al fin y al cabo el precedente administrativo emerge de la decisión estatal que, sujeta a la legitimidad de su accionar adquiere una estabilidad y fuerza superior a la costumbre civil. Esta última reconoce tantos ajustes como cambios sociales y culturales se registren en una comunidad, en tanto que el principio de juridicidad limita los cambios de las formas de resolver las cuestiones en la administración a la aplicación expresa de la legislación competencial positiva.

Es nada más y nada menos que conocimiento empírico en estado puro. Los innumerables recursos tecnológicos han revalorizado y acortado la distancia entre el saber experiencial y el científico. La sistematización de los casos particulares hace ciencia y el derecho se nutre de ella. Controvertir la corriente precedente de resoluciones implica la obligación estatal de esforzar la argumentación motivadora de sus actos administrativos, conllevando es un límite tácito - al menos por ahora, en nuestro derecho público positivo de la discrecionalidad y una garantía más de los derechos de los particulares.

\footnotetext{
${ }^{29}$ Ley 27445 del Procedimiento administrativo general. Artículo VI.Precedentes administrativos

1. "Los actos administrativos que al resolver casos particulares interpreten de modo expreso y con carácter general el sentido de la legislación, constituirán precedentes administrativos de observancia obligatoria por la entidad, mientras dicha interpretación no sea modificada. Dichos actos serán publicados conforme a las reglas establecidas en la presente norma; 2. Los criterios interpretativos establecidos por las entidades, podrán ser modificados si se considera que no es correcta la interpretación anterior o es contraria al interés general. La nueva interpretación no podrá aplicarse a situaciones anteriores, salvo que fuere más favorable a los administrados;
}

3. En todo caso, la sola modificación de los criterios no faculta a la revisión de oficio en sede administrativa de los actos firmes".

${ }^{30}$ Ley 1437 de 2011 Diario Oficial No. 47.956 de 18 de enero de 2011: Artículo 10. DEBER DE APLICACIÓN UNIFORME DE LAS NORMAS Y LA JURISPRUDENCIA. Artículo CONDICIONALMENTE EXEQUIBLE "Al resolver los asuntos de su competencia, las autoridades aplicarán las disposiciones constitucionales, legales y reglamentarias de manera uniforme a situaciones que tengan los mismos supuestos fácticos y jurídicos. Con este propósito, al adoptar las decisiones de su competencia, deberán tener en cuenta las sentencias de unificación jurisprudencial del Consejo de Estado en las que se interpreten y apliquen dichas normas". 